Laporan Kasus

\title{
Prosedur penatalaksanaan celah bibir inkomplit bilateral dan rinoplasti primer dengan modifikasi Mulliken
}

\author{
Al Hafiz, Debby Apri Grecwin \\ Departemen Ilmu Kesehatan Telinga Hidung Tenggorok-Bedah Kepala Leher \\ Fakultas Kedokteran Universitas Andalas/ Rumah Sakit Dr. M. Djamil \\ Padang
}

\begin{abstract}
ABSTRAK
Latar belakang: Celah bibir dengan atau tanpa celah lelangit merupakan abnormalitas perkembangan kraniofasial yang paling sering terjadi. Kelainan ini bisa unilateral atau bilateral, dan mungkin disertai dengan anomali kongenital lain. Celah bibir bilateral berpotensi mengubah struktur dan bentuk wajah serta menyebabkan gangguan dalam perkembangan makan, bicara, gigi geligi, dan kosmetik. Celah bibir selalu disertai dengan deformitas hidung, termasuk pada kasus celah bibir inkomplit. Mulliken adalah pionir yang melakukan perbaikan celah bibir bilateral dan rinoplasti primer dalam satu tahap operasi. Tujuan: Mengetahui keberhasilan operasi celah bibir inkomplit bilateral dan rinoplasti primer dengan teknik modifikasi Mulliken. Laporan kasus: Dilaporkan satu kasus celah bibir inkomplit bilateral pada anak laki-laki usia 7 bulan yang ditatalaksana dengan teknik modifikasi Mulliken. Metode: Telaah literatur berbasis bukti mengenai perbaikan celah bibir inkomplit bilateral dan rinoplasti primer dengan teknik modifikasi Mulliken melalui database Cochrane library, Pubmed Medline, dan hand searching. Hasil: Pertumbuhan nasal tip projection, nasal width, columellar length, upper lip height, cutaneous lip height, dan vermilion-mucosal height mendekati nilai normal. Kesimpulan: Prosedur celah bibir inkomplit bilateral disertai rinoplasti primer dengan teknik modifikasi Mulliken memberikan hasil yang baik.
\end{abstract}

Kata kunci: celah bibir inkomplit bilateral, teknik Mulliken, rinoplasti primer

\section{ABSTRACT}

Introduction: Cleft lip with or without cleft palate is the most common disorder of craniofacial development. This disorder could be occurred unilaterally or bilaterally, and sometimes were also accompanied by other type of congenital disorders. Bilateral cleft lip potentially could change the face structure and-shape, causing interference in eating, speech, dental development, and aesthetics. Cleft lip always occurred with nasal deformity, even in incomplete cleft lip. Mulliken is a pioneer in performing a repair in bilateral cleft lip and primary rhinoplasty altogether at the same time. Purpose: To find out the result of surgery procedure in bilateral incomplete cleft lip and primary rhinoplasty using Mulliken modification technique. Case report: A bilateral incomplete cleft lip case in a 7 months old boy and managed by Mulliken modification technique. Method: Evidence based literature study of bilateral incomplete cleft lip and primary rhinoplasty with Mulliken modification technique through Cochrane library, Pubmed Medline, and hand searching. Result: The growth of nasal tip projection, nasal width, collumellar length, upper lip height, cutaneus lip height, and vermilion mucous height were close to normal size. Conclusion: Procedure of bilateral incomplete cleft lip and primary rhinoplasty repair using Mulliken modification technique delivered a good outcome.

Keywords: bilateral incomplete cleft lip, Mulliken technique, primary rhinoplasty

Alamat korespondensi: Debby Apri Grecwin. Email: apri_grec@yahoo.com. Bagian THT-KL Fakultas Kedokteran Universitas Andalas/ RSUP dr. M. Djamil, Padang. 


\section{PENDAHULUAN}

Celah bibir dengan atau tanpa celah lelangit merupakan abnormalitas perkembangan kranio-fasial yang paling sering terjadi. ${ }^{1,2}$ Kelainan ini bisa unilateral atau bilateral dan mungkin disertai dengan anomali kongenital lain yang menjadi bagian dari suatu sindrom genetik. ${ }^{3,4}$ Celah bibir terjadi kira-kira 1:700 kelahiran hidup. ${ }^{5}$ Insiden celah bibir bilateral kira-kira 1:5.0006.500 kelahiran hidup, dan $25 \%$ kasus adalah inkomplit. ${ }^{6}$

Celah bibir bilateral berpotensi mengubah struktur dan bentuk wajah secara signifikan serta menyebabkan gangguan dalam perkembangan makan, bicara, gigi geligi, dan kosmetik. Selain dampak fisik, celah bibir juga memberikan efek psikologis dan sosio-ekonomis pada pasien dan keluarga, sehingga menyebabkan penurunan kualitas hidup. $^{4}$

Variasi metode operasi celah bibir bilateral secara primer telah banyak dikembangkan, tetapi hasilnya sering tidak adekuat. Banyak bayi yang lahir dengan celah bibir bilateral menjalani prosedur yang konvensional, multi-tahap dan memerlukan tindakan revisi saat anak-anak dan dewasa. Salah satu prinsip repair celah bibir bilateral modern adalah melakukan repair bibir dan rinoplasti primer secara bersamaan. ${ }^{6,7}$

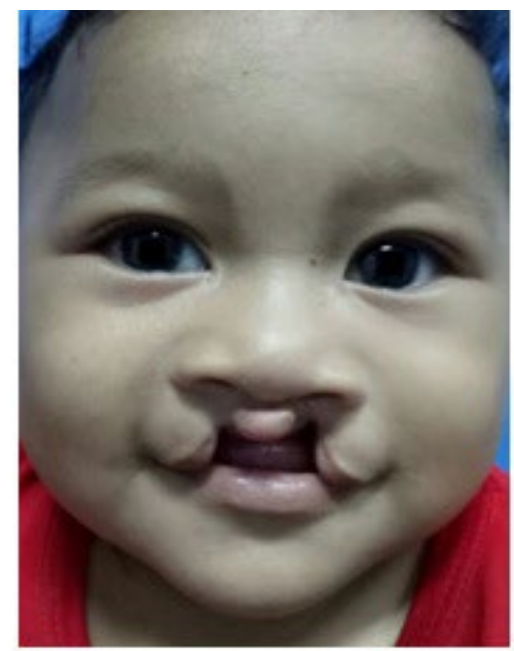

Gambar 1. Foto pasien tampak depan
Tujuan diajukannya laporan kasus ini adalah untuk mengetahui keberhasilan operasi celah bibir inkomplit bilateral dan rinoplasti primer dengan teknik modifikasi Mulliken.

\section{LAPORAN KASUS}

Seorang anak laki-laki usia 7 bulan dibawa oleh orang tuanya ke Poliklinik Telinga Hidung Tenggorok-Bedah kepala Leher (THT-KL) Rumah Sakit Umum Pemerintah (RSUP) Dr. M. Djamil, Padang tanggal 15 Maret 2018 dengan keluhan utama bibir sumbing sejak lahir. Riwayat keluar ASI dan makanan dari hidung, riwayat tersedak saat makan tidak ada. Riwayat keluarga dengan bibir dan lelangit sumbing tidak ada.

Status generalis dalam batas normal, BB 8,6 kg. Hidung: ala nasi sisi kiri tampak sedikit lebih lebar dan lebih datar dibandingkan sisi kanan. Tampak celah pada bibir meluas hingga ke bawah nasal sill, ukuran $\pm 10 \times 5$ $\mathrm{mm}$, simetris bilateral. Defek minimal pada prosesus alveolaris sisi kanan dan kiri, tidak meluas ke lelangit. Tidak tampak kelainan kongenital di bagian tubuh yang lain.

Pasien direncanakan untuk dilakukan operasi celah bibir dan rinoplasti primer dalam anestesi umum. Sebelumnya diperiksa laboratorium lengkap dengan hasil dalam batas normal dan pasien dikonsulkan ke Bagian Anak dan Anestesi untuk toleransi operasi. Tanggal 4 April 2018 dilakukan operasi celah bibir dan rinoplasti primer dengan teknik modifikasi Mulliken. Pasien tidur dalam anestesi umum, dilakukan tindakan aseptik dan antiseptik, dilakukan marking pada alar base, columellar base, prolabium, dan lateral lip elements. Infiltrasi di kedua sudut bibir dan kedua arteri angularis dengan epinefrin dan lidokain 1:100.000. Insisi pada garis marking di prolabium untuk membuat flap philtrum dan elevasi ke arah subnasal. De-epitelisasi prolabium pada kedua sisi lateral flap philtrum. Insisi kedua lateral lip elements mulai dari alar base hingga 
vermilion-cutaneous junction untuk membuat flap lateral dan flap medial (mukosa). Otot orbicularis oris dibebaskan dari kulit dan mukosa, kemudian dijahit dengan vicryl 4.0 di garis tengah. Kedua flap medial (mukosa) dijahit pada garis tengah di atas pre-maksilaris dan di bawah prolabium untuk membentuk median tubercle. Dilakukan advancing kedua flap lateral ke lateral prolabium. Flap philtrum dijahit dengan kedua sisi lateral lip elements (vermilion-cutaneous junction) untuk membentuk Cupid's bow. Dilakukan insisi pada kedua alar base secara horizontal ke arah kolumela, reseksi kedua ujung medial, lalu dijahitkan ke kolumela. Dilakukan insisi pada kedua vestibulum, kartilago lateral inferior dibebaskan, dilakukan penjahitan interdomal, genu dan crus medial dengan vicryl 4.0, sehingga ala nasi tampak simetris. Kulit dijahit dengan prolene 5.0.

Pasca operasi, diberikan diet makanan cair dengan sendok bila bising usus normal, IVFD Ka-En 1B 10 tetes/ menit, ceftriaxone 2 x $200 \mathrm{mg}$, parasetamol sirup 3 x $100 \mathrm{mg}$.
Satu hari pasca operasi, edema minimal di daerah sekitar operasi, luka operasi tenang. Pasien dibolehkan pulang, diberikan terapi cefixime sirup $100 \mathrm{mg} 2 \times 1 / 2$ sendok teh, parasetamol sirup $3 \times 100 \mathrm{mg}$ dan salep kloramfenikol 1\%. Pasien disarankan kontrol ke poliklinik THT-KL.

Satu minggu pasca operasi, dilakukan buka jahitan dalam anestesi umum, tampak sikatriks minimal pada bekas insisi.

\section{RUMUSAN MASALAH}

Apakah modifikasi Mulliken merupakan teknik yang tepat untuk celah bibir inkomplit bilateral dan rinoplasti?

\section{METODE}

Pencarian literatur dilakukan dengan kata kunci "repair bilateral incomplete cleft lip" AND "primary rhinoplasty" AND "Mulliken modified technique" melalui
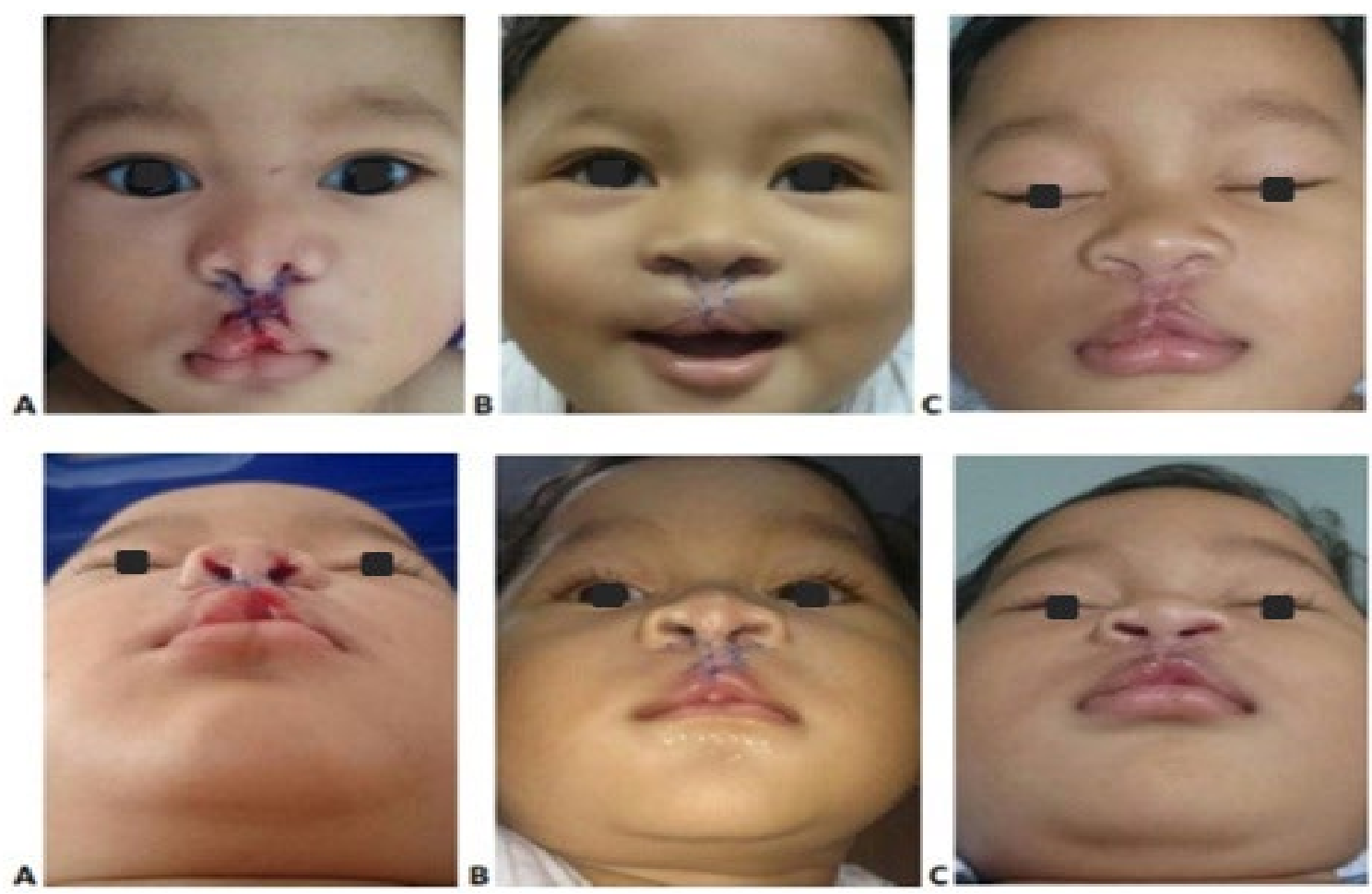

Gambar 2. A. Foto pasca operasi, B. Foto 1 minggu pasca operasi, C. Foto pasca angkat jahitan 
database Cochrane library, Pubmed, dan hand searching.

Hasil pencarian literatur diseleksi dengan menggunakan kriteria inklusi sebagai berikut: 1) pasien anak dengan celah bibir inkomplit bilateral. 2) repair celah bibir dan rinoplasti primer dalam waktu bersamaan dengan modifikasi teknik Mulliken. Kriteria eksklusi pada pasien celah bibir komplit dan asimetris bilateral. Telaah kritis dilakukan pada 2 literatur.

\section{HASIL}

Penelitian antropometri yang dilakukan oleh Kim, ${ }^{8}$ di Korea (1997-2002) pada 30 pasien (12 diantaranya tipe inkomplit) pasca operasi celah bibir bilateral dan deformitas nasal, menyimpulkan bahwa kebanyakan pasien menunjukkan pertumbuhan yang adekuat dari nasal tip protusion, nasal width, dan columellar length. Upper lip height, cutaneous lip height, dan vermilion-mucosa height mendekati nilai normal saat usia 5 tahun.

Penelitian lain yang juga dilakukan oleh Kim, ${ }^{9}$ (1997-2007) pada 44 pasien (17 pasien tipe inkomplit) yang menjalani operasi celah bibir bilateral dan deformitas nasal dalam waktu bersamaan mendapatkan nasal tip projection, upper lip height dan vermilion-mucosal height dalam batas normal. Bagaimanapun, columellar lenght dan cutaneous lip height relatif lebih pendek dibandingkan nilai rata-rata anak tanpa celah bibir bilateral.

\section{DISKUSI}

Telah dilakukan repair celah bibir inkomplit bilateral pada anak laki-laki usia 7 bulan. Insiden celah bibir bilateral 1 per 5.000-6.500 kelahiran hidup dengan laki-laki lebih banyak dibandingkan wanita. ${ }^{6,10}$
Etiologi celah bibir pada pasien ini tidak diketahui dengan pasti, dari anamnesis diperoleh data saat hamil, ibu tidak pernah menderita sakit yang berat, tidak merokok dan mengkonsumsi obat-obatan yang bersifat teratogenik, dan tidak ada riwayat keluarga yang menderita celah pada mulut atau wajah. Celah bibir dan lelangit disebabkan oleh interaksi faktor genetik dan lingkungan. ${ }^{10}$

Deformitas kongenital yang lain tidak ditemukan pada pasien. Celah bibir dan lelangit sering dihubungkan dengan sindrom, terutama celah lelangit terisolasi. Celah bibir dengan atau tanpa celah lelangit dikaitkan dengan lebih dari 200 sindrom genetik. Bentuk sindrom yang paling sering adalah Van der Wound syndrome. ${ }^{11}$ Adeyemo, ${ }^{2}$ di Nigeria mendapatkan 5 kasus celah dengan sindrom dari 39 kasus celah bibir bilateral yang dilakukan operasi dengan teknik modifikasi Millard. Widodo DN,${ }^{12}$ melaporkan satu kasus labiognatopalatoskizis komplit bilateral yang berhasil ditatalaksana dengan penggunaan nasoalveolar molding sebelum tindakan operasi dengan teknik Millard modifikasi.

Pasien menderita celah bibir inkomplit bilateral simetris. Celah bibir ini merupakan bentuk yang jarang dan biasanya berhubungan dengan celah kecil pada alveolar. ${ }^{13}$ Di antara celah bibir bilateral, varian ini yang paling mudah untuk dilakukan repair. ${ }^{6}$ Richardson, ${ }^{14}$ mendapatkan celah bibir inkomplit sebanyak 25,7\% dari 284 pasien celah bibir dan lelangit bilateral non sindrom.

Saat datang ke Poliklinik THT-KL, pasien berumur 7 bulan dan belum mendapatkan penatalaksanaan. Hal ini disebabkan oleh tidak adanya gangguan makan dan minum serta keluhan lain yang berhubungan dengan celah kongenital orofasial. Bayi dengan celah bibir dan alveolar unilateral atau bilateral umumnya tidak memiliki masalah saat minum susu, baik dari ibu maupun dari dot. ${ }^{15}$ Penatalaksanaan bayi baru lahir dengan celah bibir adalah memastikan feeding dan nutrisinya adekuat. Bila celah terlalu lebar, 
atau pre-maksilaris yang terlalu menonjol terutama pada celah bibir komplit bilateral, bisa dilakukan pre-surgical orthopedics dan lip adhesi. Manfaat pre-surgical orthopedic adalah untuk membantu mendapatkan kesegarisan pre-maksilaris, memudahkan repair otot dan membantu koreksi deformitas hidung. ${ }^{6,12}$

Pada pasien kami repair dilakukan saat usia 7 bulan. Beberapa kepustakaan menyatakan repair dilakukan saat usia pasien 3-6 bulan dan memenuhi "aturan 10", yakni usia $>10$ minggu, berat badan $>10$ pon dan hemoglobin $>10 \mathrm{mg} / \mathrm{dl} .{ }^{15}$ Repair celah bibir saat usia dini disarankan untuk menghindari dampak psikososial pada anak dan keluarga. ${ }^{2}$

Repair celah bibir bilateral dua kali lebih sulit dibandingkan celah unilateral, dengan lima puluh persen kasus yang berhasil baik. Hal ini disebabkan oleh (1) malposisi kartilago lateral inferior, (2) deposisi fibroadiposa antara kartilago lateral inferior, (3) hipoplasia kolumela, (4) protrusio pre-maksilaris dan (5) prolabium yang amuskuler. ${ }^{6,16}$

Teknik repair yang digunakan adalah modifikasi Mulliken. Teknik ini dipilih karena bisa melakukan repair bibir dan deformitas hidung dalam satu tahap operasi. Celah bibir selalu memengaruhi bentuk hidung. ${ }^{15}$ Meskipun inkomplit, pada pasien kami didapatkan deformitas hidung yang tidak terlalu jelas, yakni alar nasi sisi kiri tampak lebih lebar dan lebih datar dibandingkan sisi kanan. Perbedaan yang sedikit antara dua sisi bibir dan hidung akan menjadi lebih jelas seiring pertumbuhan. ${ }^{6}$ Mulliken adalah pionir repair celah bibir bilateral dengan deformitas hidung. ${ }^{17}$ Kerugian teknik Mulliken ini adalah terbentuknya sikatriks sepanjang alar rim. ${ }^{16}$

Ada beberapa teknik operasi celah bibir bilateral, di antaranya teknik Millard, Manchester, dan Veu. Teknik Manchester lebih mudah dilakukan dan digunakan untuk repair celah bibir bilateral inkomplit atau pada kasus dengan kolumela yang berkembang relatif baik, sedangkan teknik Mulliken digunakan pada kasus dengan kolumela yang tidak berkembang dengan baik dan deformitas hidung yang berat. ${ }^{6,16}$

Beberapa penelitian pasca repair bibir dan rinoplasti primer dengan teknik Mulliken melaporkan analisis antropometri meliputi panjang hidung, protusio bibir, dan lebar kolumela mendekati nilai normal. ${ }^{4}$ Richardson, ${ }^{14}$ melakukan penelitian di India mengenai repair celah bibir dengan teknik Mulliken mendapatkan hasil yang sangat memuaskan, baik secara medis maupun non medis. Khochtali, ${ }^{18}$ di Tunisia mendapatkan hasil yang tidak memuaskan dari repair celah bibir bilateral dengan teknik Mulliken tanpa rinoplasti primer berupa short columella dan flattened nose.

Dari laporan kasus ini dapat disimpulkan celah bibir inkomplit bilateral diklasifikasikan menjadi sindrom dan non sindrom dengan etiologi yang multifaktorial. Teknik modifikasi Mulliken untuk penatalaksanaan celah bibir disertai deformitas nasal pada kasus ini memberikan hasil yang baik.

\section{DAFTAR PUSTAKA}

1. Martelli DRB, Machado RA, Swerts MSO, Rodrigues LAM, Aquino SND, Junior HM. Non sindromic cleft lip and palate: relationship between sex and clinical extension. Braz J Otorhinolaryngol. 2012; 78(5): 116-20.

2. Adeyemo WL, James O, Adeyemi MO, Oguniewe MO, Ladeinde AL, Butali A, et.al. An evaluation of surgical outcome of bilateral cleft lip surgery using a modified Millard's (Fork Flap) technique. Afr J Paediatr Surg. 2013;10(4):307-10

3. Capone RB, Ames JA, Sykes JM. Evaluation and management of cleft lip and palate disorder. In: Papel ID, Frodel JL, Holt GR, et al, editors. Facial Plastic and Reconstructive Surgery. Fourth edition. New york: Thieme; 2016. p. 875-95. 
4. Shkoukani MA, Chen M, Vong A. Cleft lip - a comprehensive review. frontiers in pediatrics. 2013;1:1-10

5. Costello BJ, Ruiz RL. Comprehensie Management of Facial Cleft. In: Fonseca RJ, editor. Oral and Maxillofacial Surgery. Third edition. Missouri: Elsevier; 2014. p. 491-509

6. Mulliken JB. Repair of bilateral cleft lip. In: Nelligan PC, Buck II DW, editors. Core Procedures in Plastic Surgery. Third Edition. London: Elsevier; 2014. p. 550-68

7. Allori AC, Marcus JR. Modern tenets for repair of bilateral cleft lip. Clin Plast Surg. 2014;41(2):179-88.

8. Kim SK, Lee JH, Lee KC, Park JM. Mulliken Method of Bilateral Cleft Lip Repair: Anthropometric Evaluation. Plastic and Reconstruction Surgery. 2005;116(5):124351

9. Kim SK, Kim MH, Kwon YS, Lee KC. Long term results in the bilateral cleft lip repair by Mulliken's Method. J Craniofac Surg. 2009;20(5):1455-61

10. Davit AJ, Otteson T, Losee JE. Comprehensive cleft care. In: Johnson JT, Rosen CA, Newlands, Amin M, Branstetters $\mathrm{B}$, Casselbrant M, et al, editor. Baileys head and neck surgery otolaryngology. Fifth edition. Philadelphia: Lippincot William \& Wilkin; 2014. p 1556-73.

11. Muhamad AH, Azzaldeen A, Watted N. Cleft lip and palate: a comprehensive review. International Journal of Basic and Applied Medical Sciences. 2014; 4(1):33855.
12. Widodo DN, Anatriera, Cornain TZ. Tatalaksana komprehensif prosedur Millard modifikasi dengan nasoalveolar molding pada labiognatopalatoskizis komplit bilateral. ORLI. 2018;48(1):88-94

13. Yuzuriha S, Oh AK, Mulliken JB. Asymmetrical bilateral cleft lip: Complete or incomplete and contralateral lesser defect (mini-form, microform, or minimicroform). Plast and Reconstr Surg. 2008;122:1494-504.

14. Richardson S, Krishna S. Evaluation of esthetic outcome following bilateral cleft lip repair using the Mulliken technique: An assessment of 284 cases. Journal of cleft lip palate and craniofacial anomalies. 2017;4(1):94-7.

15. Goldstein JA, Losee JE. Pediatric Plastic Surgery. In: Zitelli and Davis' Atlas of Pediatric Physical Diagnosis. Seventh Edition. Elsevier; 2018. p. 845-67

16. Nangole FW, Khainga SO. Retrospective review of patients operated on with bilateral cleft lip through surgical outreaches in Kenya. ISRN Plastic Surgery. 2013;1-4.

17. Lim JS, Lee GT, Jung YS. Repair of bilateral cleft lip and nose by the Mulliken method: a case report. J Korean Assoc Oral Maxillofac Surg. 2012;38:360-5.

18. Khochtali H, Naija S, Ayadi A, Rjeb MB, Maatemri W, Mziou Z, et al. One-stage repair for bilateral cleft lip. Int J Oral Maxillofac Surg. 2018;42(10): 1199. 